\section{Outcome of breech deliveries in Aminu Kano Teaching Hospital, Kano State, Nigeria: A 2-year study}

\author{
Zainab Datti Ahmed, ${ }^{1,2}$ Haruna Usman, \\ Natalia Adamou, 1,2 \\ Hadiza Shehu Galadanci, ${ }^{1,2}$ \\ ${ }^{1}$ Department of Obstetrics and \\ Gynecology, Aminu Kano Teaching \\ Hospital, Kano; ${ }^{2}$ Department of \\ Obstetrics and Gynecology, Faculty of \\ Clinical Sciences, College of Health \\ Sciences, Bayero University, Kano, \\ Nigeria
}

\section{Abstract \\ Breech presentation is defined as polar} alignment of fetus in which the fetal buttocks or feet present at the maternal pelvic inlet. Breech is the most common malpresentation in pregnancy, incidence is high before term but occur in 3-4\% of term pregnancies. There is increased perinatal morbidity and mortality with breech presentation which has been linked to the prematurity, birth asphyxia due to cord accidents, congenital abnormalities, birth trauma and mode of delivery. This study was aimed at determining the incidence and outcome of breech deliveries at Aminu Kano Teaching Hospital, Nigeria. It was a retrospective analysis of breech deliveries at Aminu Kano Teaching Hospital over a 2-year period. Information was obtained from the labor ward register, theatre register and the case notes of the mothers. There were 6658 deliveries during the period of the study, out of which 154 had breech deliveries. The incidence of breech deliveries during the period under study was $2.31 \%$. The age of the patients ranged from 17-45 years. Parity ranged between $0-11$. There were more breech deliveries in the multipara $(59.5 \%)$ than in primigravidae $(14.9 \%)$ and primipara $(25.6 \%)$.However, there was no significant difference in the perinatal outcome between the groups $(\mathrm{P}=0.054)$. Deliveries were mostly through caesarean section (62\%), while 38\% were through assisted vaginal breech. There were 113 live births and 8 still births. This study has shown that the incidence of breech is slightly lower than in many studies, and breech deliveries were mostly unplanned and more among multiparae. The neonatal outcomes in the planned breech deliveries were excellent. Birth asphyxia and stillborn were found more in the unplanned and unbooked cases with breech.

\section{Introduction}

Breech presentation is defined as polar alignment of fetus in which the fetal buttocks or feet present at the maternal pelvic inlet. ${ }^{1-4}$ Three types of Breech Presentations are recognized, frank, flexed and footling. ${ }^{1-}$ ${ }^{5}$ Breech is the most common malpresentation in pregnancy, incidence is high before term but occur in $3-4 \%$ of term pregnancies. $^{1-5}$ Most cases of persistent Breech presentation are idiopathic, however there are predisposing factors; uterine abnormalities, uterine fibroids, placenta praevia, multiple pregnancies, prematurity, contracted pelvis, high parity, oligo and polyhydramnios, maternal smoking, IUGR, previous breech delivery, maternal drug and alcohol abuse, anticonvulsants rarely congenital malformation. ${ }^{1-3}$ These etiologic risk factors are only identifiable only in $7-15 \%$ of breech presentations. ${ }^{3,6}$ It is now thought that the majority of breech presentations have genetic predisposition without any anatomical cause. ${ }^{5}$

Increased perinatal morbidity and mortality with breech presentation is well recognized, this has been linked to the prematurity, birth asphyxia due to cord accidents, congenital abnormalities, birth trauma and mode of delivery. Even after term breech presentation generate controversies concerning the best mode of delivery especially in the tropics. ${ }^{7-10}$ It is therefore very pertinent to carefully choose and plan the route of delivery during antenatal care or early labour. ${ }^{11}$ This is even more important in our environment where there is strong aversion to caesarean section. ${ }^{8,12}$ In most developing countries, many women with breech presentation present in labor without any prior form of antenatal care and so are not diagnosed before the onset of labour. ${ }^{13}$ Therefore, obstetricians in this region are faced with the challenge of not having enough time to plan for the best way to deliver the breech. ${ }^{10,14}$ This and many other factors are important in the management of breech presentation and significantly may influence the reproductive outcome in this region. ${ }^{10,14,15}$

Breech delivery irrespective of the route is associated with maternal morbidity, perinatal morbidity and mortality. ${ }^{11}$ The morbidity and mortality are generally reported higher with vaginal route especially when it is unplanned. ${ }^{16}$

Many procedures and techniques have been employed to improve perinatal outcome, which include routine caesarean section for all babies in breech presentation, ECV and knee-chest position. . $^{3,5,12,16}$

Term breech trial remains source of concern as it is reported to significantly
Correspondence: Zainab Datti Ahmed, Department of Obstetrics and Gynecology, Aminu Kano Teaching Hospital, Kano State, Nigeria.

Tel.: +234.803.7270843.

E-mail: zainabdatti@yahoo.com

Key words: breech presentation, fetal outcome.

Contributions: the authors contributed equally.

Conflict of interest: the authors declare no potential conflict of interest.

Funding: none.

Received for publication: 22 July 2018.

Revision received: 17 October 2018.

Accepted for publication: 17 October 2018.

This work is licensed under a Creative Commons Attribution NonCommercial 4.0 License (CC BY-NC 4.0).

(C) Copyright Z.D. Ahmed et al., 2018

Licensee PAGEPress, Italy

Pyramid Journal of Medicine 2018; 1:7 doi:10.4081/pjm.2018.7

increase the overall rate of caesarean section. ${ }^{17,18}$ Therefore, external cephalic version which has been demonstrated to be associated with a significant reduction in the risk of caesarean section without any increased risk to the baby has been advocated. ${ }^{5,7,19-21}$ It is recommended that all women with an uncomplicated breech pregnancy at term (37-42 weeks) should be offered ECV. ${ }^{7,22}$ Other criteria to be fulfilled include the following; No identifiable obstetrics risk, the patient has to give consent, the breech should be Complete/frank breech, there should be a reassuring CTG, fetal head should not be engaged, ultrasound scan should be available and also facilities for emergency caesarean section should be in place. However external cephalic version is not popular in the tropics. ${ }^{23,24}$

\section{Objectives}

This study was undertaken to determine incidence and outcome of breech deliveries at Aminu Kano Teaching Hospital.

\section{Materials and Methods}

The study was carried out in the Obstetrics and Gynecology Department of Aminu Kano Teaching Hospital, Kano. It covered a period of 2 years from January 2015 to December 2016. This was a retrospective analysis of breech deliveries at 
Aminu Kano Teaching Hospital. Information on sociodemographic variables of the mother, which included maternal age, ethnicity, parity and booking status were obtained. The neonatal variables which included sex, birth weight, Apgar score and neonatal outcome were extracted. Furthermore, number of fetuses and gestational age were obtained. This information was obtained from the labor ward register, theatre register and the case notes of the mothers (Table 1). Data obtained was analyzed using statistical package for the social sciences (SPSS) statistical software version 23.Descriptive statistics were used for categorical variables and chi-square test was used to test for significance. Level of significance was set at $5 \%$

\section{Results}

There were 6658 deliveries during the period of the study, out of which 154 have breech deliveries. One hundred and twenty one out of 154 case files were retrieved and analyzed giving retrieval rate of $78.57 \%$. The incidence of breech deliveries during the period under study was $2.31 \%$.

The age of the patients ranged from $17-$ 45 years. Parity ranged between $0-11$ with a mode of multipara. There were more breech deliveries in the multipara $(59.5 \%)$ than in primigravidae $(14.9 \%)$ and primipara $(25.6 \%)$. However, there was no significant difference in the perinatal outcome between the groups $(\mathrm{P}=0.054)$. Deliveries were mostly through caesarean section $(62 \%)$, while $38 \%$ were through assisted vaginal breech. Fetal weights ranged 1100-4500g with a mean $2883 \pm 648 \mathrm{~g}$. Fetal weight was found to be higher among the caesarean section group $(\mathrm{P}=0.012)$.

More than half of the patients were booked (59.5\%). Majority of the deliveries were not planned $100(82.6 \%)$, only 21 patients have planned deliveries among the patients studied. Accoucheurs were mostly senior registrars $(61.2 \%)$ followed by midwives $(20.7 \%)$, then registrars $(15.7 \%)$ and consultants $(2.5 \%)$. Caesarean section was the major mode of delivery of the patients with breech presentation during this period (62\%) followed by assisted breech delivery (38\%) (Table 2).

Fifty seven percent of the fetuses were males and $43 \%$ were females. Live neonates were 113 and stillbirth were 8 . Term breech deliveries accounted for $86 \%$ of all breech deliveries during the study period while preterm breech deliveries accounted for $14 \%$.Majority of the deliveries were of singleton breech $(90.1 \%)$ while multiple breech deliveries accounted for only $9.9 \%$ of the deliveries (Table 3 ).

Breech presentations was seen more in the multiparae $(59.5 \%)$, then primigravidae $(25.6 \%)$ and the primiparae followed $(14.9 \%)$. The frank breech was $71.7 \%$, complete breech was $17.9 \%$ and footling breech constitute $10.4 \%$ (Table 4 ).

There was no statistically significant association in term of five-minute APGAR score between different types of breech presentation in this study $(\mathrm{P}=0.38)$. No birth asphyxia was seen in the planned delivery group compared to the unplanned delivery group where $17 \%$ of the babies were asphyxiated $(\mathrm{P}=0.04)$. There was no difference in term of 5 minutes Apgar score between the babies delivered by different cadre of health workers $(\mathrm{P}=0.14)$. No difference in 5-minute Apgar score between the babies delivered by different mode of delivery $(\mathrm{P}=0.06)$. Term breech babies had better 5-minute Apgar score compared to preterm babies $(\mathrm{P}<0.05)($ Table 5$)$.

\section{Discussion}

The prevalence of breech delivery in this study was found to be $2.31 \%$ this was similar to what was reported in other studies. ${ }^{4,8,25}$ It was lower than $3.4 \%$ reported in Owerri Imo State and $4.45 \%$ reported in Abakaliki Ebonyi State. ${ }^{11,13}$ Studies have shown that there are higher perinatal morbidity and mortality associated with breech delivery irrespective of the mode of delivery when compared with vertex delivery. ${ }^{16}$ This was however apparent in unplanned breech deliveries. ${ }^{8,13}$ There is preponderance of breech presentation among multiparous women when compared to primiparous and primigravidae this was similar to other studies. ${ }^{3,5,8,13,14}$ It is thought that high parity predisposes to fetal breech presentation due to laxity of the abdominal muscles. $^{3}$ Contrary to this, there was higher incidence of breech deliveries among primigravidae in Sokoto as reported by Tunau et al. ${ }^{25}$ Extended breech was predominant type of during the study period accounting for 76 (71.7\%),followed by flexed breech 19 $(17.9 \%)$ and then to least extent the footling breech $11(10.4 \%)$ this pattern occurrence is similar to that found other studies. ${ }^{13,14}$ Caesaren Section rate in this study was found to be $62 \%$, this was similar to the studies by Adeyemi et al., Takai et al. and Reitberg et al.5,6,16 However, it is contrary to the studies by Duke et al. and Tunau et al., where caesarean section rates were $33.8 \%$ and $30.9 \%$ respectivelyl. ${ }^{14,24}$ The high rate of Caesarean section in this study may not be unconnected to the urgency for the need of delivery as most of the babies
Table 1. Sociodemographic characteristics (total $=121$ )

Frequency Percentage

\begin{tabular}{lcc} 
Age & & \\
$<=19$ & 4 & 3.3 \\
$20-24$ & 36 & 29.8 \\
$25-29$ & 29 & 24.0 \\
$30-34$ & 23 & 19.0 \\
$35-39$ & 22 & 18.2 \\
$40+$ & 7 & 5.8 \\
Tribe & & \\
Hausa & 94 & 77.7 \\
Yoruba & 6 & 5.0 \\
Igbo & 5 & 4.1 \\
Others & 16 & 13.2 \\
\hline
\end{tabular}

Table 2. Booking status, type of delivery, accoucheur and mode of delivery $($ total $=121)$.

\begin{tabular}{lcc} 
& Frequency & Percentage \\
Booking status & & \\
Booked & 72 & 59.5 \\
Unbooked & 49 & 40.5 \\
Type of Delivery & & \\
Planned & 21 & 17.4 \\
Unplanned & 100 & 82.6 \\
\hline Accoucheur & & \\
Midwife & 25 & 20.7 \\
Registrar & 19 & 15.7 \\
Snr Reg & 74 & 61.2 \\
Consultant & 3 & 2.5 \\
Mode of Delivery & & \\
ABD & 46 & 38.0 \\
EMCS & 55 & 45.5 \\
ELCS & 20 & 16.5
\end{tabular}

Table 3. Fetal sex, fetal outcome, gestational age and number of fetuses (total $=121)$.

\begin{tabular}{lcc} 
& Frequency & Percentage \\
Fetal Sex & & \\
$\quad$ Male & 69 & 57.0 \\
$\quad$ Female & 52 & 43.0 \\
Fetal outcome & & \\
$\quad$ Livebirth & 113 & 93.4 \\
$\quad$ Stillbirth & 8 & 6.6 \\
\hline Gestational Age & & \\
$\quad$ Term & 104 & 86.0 \\
$\quad$ Preterm & 17 & 14.0 \\
Number of Fetuses & & \\
$\quad$ Single & 109 & 90.1 \\
$\quad$ Multiple & 12 & 9.9 \\
\hline
\end{tabular}

Table 4. Parity and type of breech in the patients studied (total $=121$ ).

Frequency Percentage

$\begin{array}{lll}\text { Parity } & & \\ \text { Grandmultipara } & 27 & 22.3 \\ \text { Multiparara } & 45 & 37.2 \\ \text { Primigravida } & 31 & 25.6 \\ \text { Primiparara } & 18 & 14.9 \\ \text { Type of Breech } & & \\ \text { Frank } & 86 & 71.1 \\ \text { Complete } & 22 & 18.1 \\ \text { Footling } & 13 & 10.8\end{array}$


Table 5. Five-minute APGAR score compared with the type of breech, type of delivery, accoucheur, mode of delivery and gestational age.

\begin{tabular}{|c|c|c|c|c|c|c|}
\hline Parameters & & $\begin{array}{c}\text { GAR } \\
>6\end{array}$ & Total & $\mathrm{X}^{2}$ & df & P value \\
\hline $\begin{array}{l}\text { Type of breech } \\
\text { Frank } \\
\text { Complete } \\
\text { Footling } \\
\text { Total }\end{array}$ & $\begin{array}{c}11 \\
3 \\
0 \\
14\end{array}$ & $\begin{array}{c}75 \\
19 \\
13 \\
107\end{array}$ & $\begin{array}{c}86 \\
22 \\
13 \\
121\end{array}$ & 1.891 & 2 & 0.38 \\
\hline $\begin{array}{l}\text { Type of Delivery } \\
\text { Planned } \\
\text { Unplanned } \\
\text { Total }\end{array}$ & $\begin{array}{c}0 \\
17 \\
17\end{array}$ & $\begin{array}{c}21 \\
83 \\
104\end{array}$ & $\begin{array}{c}21 \\
100 \\
121\end{array}$ & 4.1 & 1 & 0.04 \\
\hline $\begin{array}{c}\text { Accoucheur } \\
\text { Midwife } \\
\text { Registrar } \\
\text { Snr Reg } \\
\text { Consultant }\end{array}$ & $\begin{array}{l}7 \\
2 \\
8 \\
0\end{array}$ & $\begin{array}{c}18 \\
17 \\
66 \\
3\end{array}$ & $\begin{array}{c}25 \\
19 \\
74 \\
3\end{array}$ & 5.3 & 3 & 0.14 \\
\hline $\begin{array}{c}\text { Mode of Delivery } \\
\text { ABD } \\
\text { EMCS } \\
\text { ELCS } \\
\text { Total } \\
\end{array}$ & $\begin{array}{c}10 \\
7 \\
0 \\
17\end{array}$ & $\begin{array}{c}36 \\
48 \\
20 \\
104\end{array}$ & $\begin{array}{r}46 \\
55 \\
20 \\
121 \\
\end{array}$ & 5.6 & 2 & 0.06 \\
\hline $\begin{array}{c}\text { Gestational Age } \\
\text { Term } \\
\text { Preterm } \\
\text { Total }\end{array}$ & $\begin{array}{c}9 \\
8 \\
17\end{array}$ & $\begin{array}{c}95 \\
9 \\
104\end{array}$ & $\begin{array}{c}104 \\
17 \\
121\end{array}$ & 17.4 & 2 & $<0.05$ \\
\hline
\end{tabular}

delivered via caesarean section were big babies compared to those delivered via assisted breech delivery $(\mathrm{P}=0.012)$. This is similar in other studies conducted in Nigeria. ${ }^{8,11,14}$ There was no neonatal asphyxia reported in the planned delivery arm compared to the unplanned delivery $\operatorname{arm}(\mathrm{P}=0.04)$, this may not be unconnected to their unbooked status and presentation as emergencies. Type of accoucheur was not found to be significant in the outcome of breech pregnancies in this study, this was contrary to what was found in Maiduguri where outcomes were favored by the seniority of the accoucher. ${ }^{8}$ Recently it was found that planned caesarean section for breech deliveries reduce perinatal morbidity and mortality significantly although maternal morbidity may be increased. $5,11,13$ Despite large proportion of booked patients only $17.4 \%$ of them had planned breech delivery. There is room for planned assisted breech delivery in carefully selected patients where there are selection criteria to be applied antenatally, with good neonatal outcome and less maternal morbidity. ${ }^{19,26}$ Moreover, there is strong aversion to caesarean section in this environment. ${ }^{13,25}$

\section{Conclusions}

In conclusion, this study has shown that breech deliveries were mostly unplanned and were frequent among multiparae. The neonatal outcomes in the planned breech deliveries were excellent. Significant number of women were unbooked, hence there was no plan for their delivery. The high caesarean section rate could be reduced by laying more emphasis on external cephalic version and also training and retraining of mid wives and residents on assisted breech delivery on highly selected patients with minimal complications.

\section{References}

1. John CT, Okpani OA. Breech Presentation In: Kwawukume EY, Ekele BA, Danso KA, Ejiro E, eds. Comprehensive Obstetrics in The Tropics. 2nd Edition Accra-North, Ghana. Printed by Assemblies of God Literature Centre Limited; 2015. pp 202-206.

2. Arulkumaran S. Malpresentation, Malposition, Cephalopelvic Disproportion and Obstetric Procedures In: D. Keith Edmonds Ed. Dewhurst's Textbook of Obstetrics and Gynaecology. 8th Ed. London UK: Wiley-Blackwell; 2012. pp. 311-325.

3. Cunningham GF. Breech Presentation and Delivery. In: Cunningham GF, Leveno KJ, Bloom SL, et al, Eds. Williams Obstetrics. 23rd ed. USA: McGraw-Hill Companies; 2010. pp 527-543.

4. Kish K. Malpresentation and Cord Prolapse. In: Alan HD, Lauren N, Neri
L, Ashley SR, Eds. Current Diagnosis and Treatment. 11th Ed. USA: McGraw Hill Companies; 2013.

5. Adeyemi AS, Adekanle DA, Afolabi AF, Fadero FF. Outcome of Breech Deliveries at a tertiary health institutionin southwestern Nigeria. Niger Hosp Pract 2011;7:3-7.

6. Tompkins P. An Inquiry into the Causes of Breech Presentation. Am J Obstet Gynaecol 1996;174:26-32.

7. Hayman R. Breech Presentation In: Luesley DM, Baker PN, eds. Obstetrics and Gynaecology. An Evidence Based Text for MRCOG.2nd Ed. London: Hodder Arnolds; 2010. pp 436-446.

8. Takai IU, Kwayabura AS, Bukar M, et al. A 5-Year Retrospective review of Singleton term Breech Deliveries seen at a Tertiary Hospital in Northern Nigeria. Arch Intern Surg 2016 6:7-11.

9. Hardy JR. Intergenerational Recurrence of Breech Delivery. Br Med J 2008;336: 843-4.

10. Pasupaty D, Wood AM, Pell JP, et al. Time trend in the risk of delivery- related perinatal and neonatal death associated with breech presentation at term. Int J Epidemiol 2009;38:490-8.

11. Obuna JA, Ugboma HA, Agwu UM, Ejikeme BN. The Prevalence and Outcome of Singleton Breech Delivery in Abakaliki South-East Nigeria. J Med Sci Clin Res 2014; 2:1011-22.

12. Ibekwe PC, Obuna JA. Appraisal of Indications for Caeserean Sections in Abakaliki, Nigeria. Trop J Obstet Gynaecol 2006;23:150-2.

13. Duke AO, Duke CO, Onyegbule OA, et al. Outcome of Single Term Breech Deliveries at Federal Medical Centre, Owerri, South Eastern Nigeria: A Five Year Review. Int J Res Med Sci 2014;2:527-31.

14. Fasuba OB, Orji EO, Ogunlola O, et al. Outcome of Singleton Breech Delivery in Wesley Guild Hospital, Ilesha, Nigeria. Trop J Obstet Gynaecol 2003;20:59-62.

15. Adegbola O, Akindele OM. Outcome of Term Singleton Breech Deliveries at a University Teaching Hospital in Lagos. Nig Posgrad Med J 2009;16:154-7.

16. Thorpe BJG, Banofield PJ, Saunders NJ. Outcome of Breech Delivery at Term. BMJ 1992;305:746.

17. Reitberg CC, Elferink-Stinkens PM, Visser GHA. The effect of the term breech trial on medical intervention behaviour and neonatl outcome in the Netherlands: an analysis of 35,453 term breech infants. BJOG 2005;112:205-9.

18. Sobonde A, Yousuf F, Eskender M, Almusnait MA. Breech delivery before 
and after the term breech trial recommendation. Saudi Med J 2007;28:12137.

19. Hutton EK, Saunders CA, Tu M, et al. Factors associated with a successful external cephalic version in the early ECV trial. J Obstetgynaecol 2008;30:23-9.

20. ACOG Committee on obstetric practice. ACOG Committee Opinion No.340. Mode of term singleton breech delivery. Obstet Gynecol 2006;108:235-7.

21. Kuppens SM, Francois AM, Hasaart
TH, et al. Fewer breech deliveries after implementation of a modified cephalic version protocol. Ned Tiidschr Geneeskd 2008;154:63-7.

22. Hofmeyr GJ, Hannah HM. Planned Caesarean Section for the Term Breech Delivery. Cochrane Database Syst Rev 2003:CD000166.

23. Adetoro OO, Fakaye OO. Brrech Presentation: A 3- year survey. Trop J Obstet Gynaecol 1990;8: 10-2.

24. Onah HE, Nkwo PO. External Cephalic Version: A survey of Current Practice among Nigerian Obstetricians. Trop J
Obstet Gynaecol 2004;21:24-6.

25. Tunau K, Ahmed Y. Breech deliveries in Usmanu Dan Fodio University Teaching Hospital Sokoto, Northwestern Nigeria: A 10 year Review. Sahel Med J 2013;16:52-5.

26. Goffinet F, Carayol M, Foidart JM, et al. Is planned vaginal delivery for breech presentation at term still an option? Results of an observational prospective survey in France and Belgium. Am J Obstet Gynaecol 2006;194:1002-11. 